\title{
Enlightening Idea of British and German Higher Education on the Pilot Reform of Curriculum in China
}

\author{
Authors: Jiang Qiongqin ${ }^{1 a}$, Song Wenguang ${ }^{1 b^{*}}$, Yu Gaoming ${ }^{1 c^{*}}$, \\ Zhang Jiahao
}

Cooperative Innovation Center of Unconventional Oil and Gas, Yangtze University, Ministry of Education \& Hubei Province, Wuhan, 43400, China ${ }^{1}$

E-Email:17617100@qq.com ${ }^{a}$;wenguang_song@yangtzeu.edu.cn ${ }^{b} ; y g m 1210 @ v i p . s i n a . c o m{ }^{c} ; 1614756416 @ q q$. com $^{d}$

DOI: 10.26821/IJSRC.9.7.2021.9718

\begin{abstract}
Through investigation and analysis of higher education in developed countries such as Britain and Germany, the advantages of the Western education system are analyzed from the aspects of education tort system, education personnel training mechanism and concept. In view of the current situation of China's higher education, it is proposed to adhere to the scientific concept of development, update the concept of higher education, improve the supervision and evaluation of higher education, strengthen the quality management of higher education, optimize the appointment and management of principals and teachers, provide intellectual support for educational development, optimize the learning concept and learning methods, explore and implement the tutorial system or tutor system, establish a dynamic adjustment mechanism for specialties, and optimize the structure and type of personnel training.
\end{abstract}

Keywords: Higher Education; Curriculum Reform; Hubei University Education Reform

\section{INTRODUCTION}

Through visits to several universities, secondary schools and embassy cultural and educational offices in Britain and Germany for 11 days, research work was conducted. Visits were made to the Union of British Characteristic Schools (SSAT), private schools Dulwich School, the British Council of Culture, Oxford University, the Cultural Education Department of the Embassy in Germany, the University of Bestsaibo, the University of Dove, the University of Heidelberg, the Consulate General of Frankfurt, etc. The discussion and exchange at Oxford University mainly discussed the teaching methods, teaching modes and students' learning process.

\section{Enrollment System of British and}

\section{German Universities E}

There are 168 universities in Britain. Education is decentralized to four local governments: England, Scotland, Wales and Northern Ireland. Universities are independent and autonomous. They are established through royal concessions or legislation. And most universities are public. Universities have their own curriculum and degree granting rights. The government generally does not interfere. There is no college entrance examination in Britain. It is mainly through the third-level education after primary and secondary education, which is generally the A- 
Volume 9 Issue 7 July 2021

Level (The General Certificate of Education Advanced Level) of the two-year school system to determine what kind of university students can enter in the future. The age of students at this stage is generally 16-18 years old. In the first year, learning the Advanced Subsidiary Level Examination (AS-Level), including four or five courses. In the second year, it learns the Advanced Level Examination (A2-Level), usually including three courses. In order to apply for full-time higher education courses, including basic degrees, bachelor's degrees, national higher education diplomas and national higher education certificates / diplomas in Scotland, applicants need to apply to the Enrollment Office of Colleges and Universities. General applicants can fill in up to 5 volunteers. Universities are admitted according to their ALevel scores.

There are 387 universities in Germany, including 240 national universities, 107 private universities and 40 church universities. Primary schools in Germany are all four-year. At the end of primary school, what kind of secondary school children enter is decided according to the children's learning situation. There are two types of middle school. One is arts and science school. The other is comprehensive school. Students who study in arts and science schools generally choose to enter the University for Further Study after high school graduation. As for the type of college to attend, it is mainly based on the student's performance in the whole secondary school stage. German secondary school students' grades are very different from our grades. In addition to 1-2 knowledge examinations per semester and examinations at the completion of major subjects, factors such as students' classroom discussion, social practice and homework completion should be taken into account. It is required to truly reflect the development of students' comprehensive quality during school. When applying for prestigious universities such as the University of Munich and the University of Heidelberg, you can only apply for other universities if you have the "will" but not the "performance" at the secondary school. If the university has no place in the year of application, it can wait until the second and third year. In short, as long as you want to read, there are always universities.

\section{Scientific Research at}

\section{Undergraduate Stage in Britain and}

\section{Germany}

British universities attach great importance to students' independent learning ability, so students usually need to complete a research work independently and write papers in the final year of their undergraduate course to determine the level of degree awarded. British bachelor's degree is divided into five grades: first-class honorary bachelor's degree, second-class upper honorary bachelor's degree, second-class lower honorary bachelor's degree, third-class bachelor's degree, pass bachelor's degree. If you have completed a bachelor's degree and wish to apply directly to a master's degree program, you will normally have to obtain an honorary bachelor's degree, otherwise you will have to work before applying for a master's degree.

In Oxford University, undergraduates and graduate students as well as scholars of many other disciplines study together to encourage them to transcend their boundaries. Schools provide accommodation and food, as well as academic, certain welfare and social facilities. In the undergraduate stage, it mainly teaches students some important experience. The form of tutorials usually requires a mentor (a top scholar) to spend 
Volume 9 Issue 7 July 2021

more than an hour in scientific discussions with students, once or twice a week. Students closely and regularly contact their tutors to discuss the most cutting-edge knowledge in this field. This also provides students with a highly personalized education development experience exchange opportunity. Before the discussion, students need to make strict preparations. They have their own conclusions and sufficient evidence and actively participate in the discussion. Other colleges and universities integrate the scientific research process of undergraduates into the usual teaching process, such as scientific experiments, symposiums, writing course papers, etc., in order to strengthen the cultivation of students' scientific research ability.

The field of scientific research in German universities is very extensive. They have not only basic research, but also applied research and new technology development. The entity of scientific research at German universities is the Scientific Research Group (also known as the Institute). It is equivalent to the teaching and research departments or departments in Chinese universities. College is above the research group. However, due to the almost complete decentralization of academic power, the role of the college is greatly weakened. It is only responsible for the management of some departments. The specific teaching content and teaching methods are determined by the department. The leaders of scientific research groups usually have high scientific research level, broad academic vision and great academic autonomy. Therefore, they are the most important implementers and promoters of open research in universities.

The main difference between Britain and Germany and China in scientific research is that they do not have national key laboratories. China's scientific research work is mainly concentrated in the national key laboratory.

\section{On the Enrollment System of British and German Universities}

There is no college entrance examination in Britain. When enrolling students in universities, they mainly focus on process management according to the performance of students during their study, and enter different schools according to the A-Level (The General Certificate of Education Advanced Level) score. A-Level test is similar to the college entrance examination in China, but it is different in requirements and contents. Dulwich School focuses on cultivating students' personality and specialty. Every year, $12 \%$ of the students can enter Oxford University.

German pupils can choose different secondary schools according to their grades in the fourth grade. University enrollment is mainly based on its national conditions, that is, the basis of a large manufacturing country. Most of the students in general liberal arts schools continue to study in universities. The diploma of liberal arts high school is universal in all federal states. The senior department of arts and science high school has the nature of college preparatory. They have many internships and long hours during their studies, and develop strong practical ability. After graduation, they can either enter a university or work directly in a company. Most of the students in comprehensive schools enter vocational and technical schools and work directly after graduation. College entrance examination is divided into before the Spring Festival and June.

\section{Enlightening Ideas}

\subsection{Introducing Process Management and Assessment Mechanism into}


Volume 9 Issue 7 July 2021

\section{University Courses in Hubei Province to}

\section{Improve Teaching Quality}

In education in the UK and Germany, it pays great attention to grades when students go to school and graduate. This result is the final result of the process assessment. It consists of usual assignments, seminars, essays, curriculum design and other content. It is not similar to Chinese final exam results.

The usual scores accounted for 40\%-50\%, and the examinations accounted for $50 \%-60 \%$. Start from several courses. Focus on process management. The usual share of performance increases.

\subsection{Universities in Hubei Province can} gradually pilot tutor system or tutor system to strengthen innovative education

It is suggested to pilot and gradually promote the tutorial system or tutor system in some universities in Hubei. That is, the relevant professors, associate professors, doctors and lecturers of relevant majors form a tutor group system to tutor students for one or two weeks. And the approach will be gradually promoted.

It is British university tutorial system originated in Oxford University. Since the Middle Ages, it is still the core and foundation of undergraduate teaching in Oxford University, and it is also the key to the quality of first-class undergraduate teaching. The process of tutor teaching in Oxford University focuses on cultivating students' ability to view things, evaluate evidence and analyze facts. In the process of preparing the thesis, students learn how to collect data independently and express them coherently. At the same time, in the process of tutor teaching, they learn how to defend their views and positions in front of tutor criticism.

British universities are generally three-year. In addition to teaching in class, students after class are guided by the tutor. In fact, in addition to 8 hours of classroom learning, the task assigned by the tutor is more than us. Students have heavy tasks after class.

The school system is three years. Oxford University has departments of physics and mathematics. These two departments are responsible for the classroom management of their departments. The college manages things outside the classroom. Starting from the experimental classes and pilot colleges, how to supervise students to follow the tutor to study. It is suggested that the system be strictly formulated and the promotion of mentoring be encouraged.

\subsection{A Pilot Teaching Method without}

\section{Teaching Materials for Specialized}

\section{Courses in Some Universities of Hubei}

\section{Province}

As a compilation, the textbook only represents the head of a family. In Hubei Province, undergraduate and postgraduate courses in some universities do not require textbooks. A special topic can be left for students to complete selfexamination and research to exercise their practice and innovation ability. Teaching without textbooks is the first pilot among postgraduates. Teachers teach key points and leave homework, such as Yangtze University software engineering, software architecture design process report.

\section{ACKNOWLEDGMENTS}

This work was supported by Xinjiang Uygur Autonomous Region Innovation Environment (talent, base) Construction Foundation (Xinjiang 
Volume 9 Issue 7 July 2021

NSFC Program Foundation 2020D01A132): Research and implementation of horizontal inversion optimization interpretation method. Hubei Science and Technology Demonstration Foundation (2019ZYYD016). Cooperative Innovation Center of Unconventional Oil and Gas, Yangtze University (Ministry of Education \& Hubei Province), NO UOG2020-10.Logging simulation of gas water two-phase production in shale gas horizontal wells (2020CB21-25). Digital core graphic virtual simulation teaching system based on Alicloud. Ideological and political education of postgraduate courses in Yangtze University: Python for Data Analysis. Quality courses for Postgraduates in Yangtze University: Artificial Intelligence and Machine Learning.

\section{REFERENCES}

[1]Rollan Kamila,Somerton Michelle. Inclusive education reform in Kazakhstan: civil society activism from the bottom-up[J]. International Journal of Inclusive Education,2021,25(10):25-27. [2]Bo Liu. A Probe into the Application of Bisection Classroom in Higher Education[J]. International Journal of Social Science and Education Research,2021,4(7):12-16.

[3]Peng Wang, Zhigang Lv, Xiaoyan Li. Research on Practical Teaching Mode of Robot Engineering Specialty with Integration of Competitioneducation and Research-education[J]. International Journal of Social Science and Education Research,2021,4(7):43-47.

[4]Khan Arshad M.,D'Arcy Christina E.,Olimpo Jeffrey T.. A historical perspective on training students to create standardized maps of novel brain structure: Newly-uncovered resonances between past and present research-based neuroanatomy curricula[J]. Neuroscience Letters, 2021,759\{5\}:2731.
[5]Various. Routledge Library Editions: Education Mini-Set H History of Education 24 vol set[M].Taylor and Francis:2021-06-29.38-41.

[6]Sekerák Marián,Valeš Lukáš. Two steps forward, one step back: transformation of higher education policy and reforms in the Czech Republic[J]. Perspectives: Policy and Practice in Higher Education,2021,25(3):49-52.

[7]MacQuarrie Sarah,Lyon Fiona,Dawson Susan. Implementation of assessment reform: insights from minority language provision[J]. Language and Education,2021,35(4):21-25.

[8]Matthew Clarke. Education and the Fantasies of Neoliberalism:Politics, Policy and Psychoanalysis[M].Taylor and Francis:2021-0611:35-38.

[9]Rugeria Javier Leonardo V.. José María Panganiban's "La Universidad de Manila" and the Liberal Campaign for Reforms in Philippine Higher Education[J]. Philippine Studies: Historical and Ethnographic Viewpoints,2021,69(2):35-39.

[10]Wang Qinghua. "Growing Out of the Plan": Market-Oriented Reforms in China's Graduate Placement System of Higher Education, 19781994[J]. China Review,2021,21(2):51-55.

[11]Sarah Murray,Princess Allotey. Primary Mathematics Pedagogy at the Intersection of

Education Reform, Policy, and Culture:Comparative Insights from Ghana, Singapore, and the US[M].Taylor and Francis:2021-06-01:50-53.

[12]Yonah H. Matemba. Religious identity, social space, and discourses of religious education reform in Scotland and Malawi: a Bourdieusian analysis[J]. Journal of Religious Education,2021\{4\}:35-39.

[13]Bohle Leah F,Valencia Edgar,Ross Greta,Dzhabarovna Davlyatova Dilbar,Yarbaeva Shakhlo N,Kasymova Zukhra A,Prytherch Helen. 
Volume 9 Issue 7 July 2021

Medical education reform in Tajikistan: comparison of the conventional one-year family medicine residency program and the new two-year residency program for postgraduate medical education.[J]. BMC medical education,2021,21(1):28-33.

[14]Xiao Yu,Li ZhongXiang,Chen Jia,Wang Juan,Mo ZiXin,Qiu QinMing,Zhu Shan,Zhu ShaoYi. Keeping up with the pace of international doctoral education reform: China implements the application-assessment system.[J]. Postgraduate medical journal,2021, $\{4\}: 25-29$.

[15]Shenghui Qu. Research on Innovation and Entrepreneurship Education Reform in Vocational Colleges[J]. International Journal of Secondary Education,2021,9(2):38-43.

[16]Peng Du. Research on the Reform Path and Countermeasures of Vocational Education[J]. International Journal of Social Science and Education Research,2021,4(5):51-55.

[17]Shi Wenwen. Teaching Reform of Chinese International Education Major Based on Big Data of Internet of Things[J]. Journal of Physics: Conference Series,2021,1915(4):49-52.

[18]Yang Lu. Research on the Utilization of Computer Network Information Resources and the Reform of College Physical Education[J]. Journal of Physics: Conference Series,2021,1915(3):31-36.

[19]Gareth Evans. Back to the future Reflections on three phases of education policy reform in Wales and their implications for teachers $[\mathrm{J}]$. Journal of Educational Change,2021, $\{4\}: 26-31$.

[20]Jipeng Zhao,Bing Li. Research on Teacher Training System of Innovation and Entrepreneurship Education in Engineering Colleges[J]. International Journal of Education and Teaching Research,2021,2(1):30-33.
[21]Kay Louise,Wood Elizabeth,Nuttall Joce,Henderson Linda. Problematising policies for workforce reform in early childhood education: a rhetorical analysis of England's[J]. Journal of Education Policy,2021,36(2):29-33.

[22]Mampaey Jelle,De Wit Kurt,Broucker Bruno. The delegitimation of student protest against market-oriented reforms in higher education: the role of mass media discourse[J]. Studies in Higher Education,2021,46(3):35-39.

\section{Authors' Profiles}

Jiang Qiongqin was born in Huanggang, Hubei, P.R. China, in 1980. Now, she works in Yangtze University. Her research interest includes software engineering, petroleum software technology, and big data analysis. Email:17617100@qq.com.

Corresponding author Song Wenguang was born in Wuhan, Hubei, P.R. China, in 1979. Now, he works in Yangtze University. His research interest includes software engineering, petroleum software technology, and big data analysis. E-mail: wenguang_song@yangtzeu.edu.cn.

Corresponding author Yu Gaoming was born in Changsha, Hunan, P.R. China. Now, he works in Yangtze University. His research interest includes petroleum software technology. E-mail: ygm1210@vip.sina.com. 